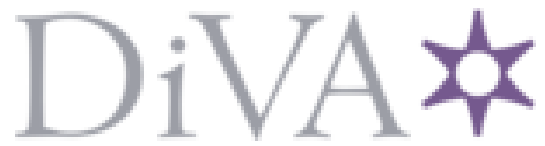

http://www.diva-portal.org

\title{
Postprint
}

This is the accepted version of a paper published in European journal of physics. This paper has been peer-reviewed but does not include the final publisher proof-corrections or journal pagination.

Citation for the original published paper (version of record):

Johansson, A. (2018)

Undergraduate quantum mechanics: lost opportunities for engaging motivated students?.

European journal of physics, 39(2)

https://doi.org/10.1088/1361-6404/aagb42

Access to the published version may require subscription.

N.B. When citing this work, cite the original published paper.

Permanent link to this version:

http://urn.kb.se/resolve?urn=urn:nbn:se:uu:diva-341687 
ACCEPTED MANUSCRIPT

\section{Undergraduate quantum mechanics: lost opportunities for engaging motivated students?}

To cite this article before publication: Anders Johansson et al 2017 Eur. J. Phys. in press https://doi.org/10.1088/1361-6404/aa9b42

\section{Manuscript version: Accepted Manuscript}

Accepted Manuscript is "the version of the article accepted for publication including all changes made as a result of the peer review process, and which may also include the addition to the article by IOP Publishing of a header, an article ID, a cover sheet and/or an 'Accepted

Manuscript' watermark, but excluding any other editing, typesetting or other changes made by IOP Publishing and/or its licensors"

This Accepted Manuscript is @ 2017 European Physical Society.

During the embargo period (the 12 month period from the publication of the Version of Record of this article), the Accepted Manuscript is fully protected by copyright and cannot be reused or reposted elsewhere.

As the Version of Record of this article is going to be / has been published on a subscription basis, this Accepted Manuscript is available for reuse under a CC BY-NC-ND 3.0 licence after the 12 month embargo period.

After the embargo period, everyone is permitted to use copy and redistribute this article for non-commercial purposes only, provided that they adhere to all the terms of the licence https://creativecommons.org/licences/by-nc-nd/3.0

Although reasonable endeavours have been taken to obtain all necessary permissions from third parties to include their copyrighted content within this article, their full citation and copyright line may not be present in this Accepted Manuscript version. Before using any content from this article, please refer to the Version of Record on IOPscience once published for full citation and copyright details, as permissions will likely be required. All third party content is fully copyright protected, unless specifically stated otherwise in the figure caption in the Version of Record.

View the article online for updates and enhancements. 


\title{
Undergraduate quantum mechanics: Lost opportunities for engaging motivated students?
}

\author{
Anders Johansson \\ Department of Physics and Astronomy, Uppsala University, Box 516, 75120 Uppsala, \\ Sweden \\ E-mail: anders.johansson@physics.uu.se \\ November 2017
}

\begin{abstract}
Quantum mechanics is widely recognized as an important and difficult subject, and many studies have been published focusing on students' conceptual difficulties. However, the sociocultural aspects of studying such an emblematic subject have not been researched to any large extent. This study explores students' experiences of undergraduate quantum mechanics using qualitative analysis of semi-structured interview data. The results inform discussions about the teaching of quantum mechanics by adding a sociocultural dimension. Students pictured quantum mechanics as an intriguing subject that inspired them to study physics. The study environment they encountered when taking their first quantum mechanics course was however not always as inspiring as expected. Quantum mechanics instruction has commonly focused on the mathematical framework of quantum mechanics, and this kind of teaching was also what the interviewees had experienced. Two ways of handling the encounter with a traditional quantum mechanics course were identified in the interviews; either students accept the practice of studying quantum mechanics in a mathematical, exercise-centred way or they distance themselves from these practices and the subject. The students who responded by distancing themselves experienced a crisis and disappointment, where their experiences did not match the way they imagined themselves engaging with quantum mechanics. The implications of these findings are discussed in relation to efforts to reform the teaching of undergraduate quantûm mechanics.
\end{abstract}

Keywords: physics education, quantum mechanics, sociocultural issues, identity

Submitted to: Eur. J. Phys.

\section{Introduction}

In undergraduate physics education, the first course in quantum mechanics is a central step towards becoming a physicist. It is essential for many modern physics applications, and also a formal requirement for most bachelor's degrees (Ferdinande, 2009). However, quantum mechanics is also recognized as a difficult subject and the subtleties of understanding it indepth have been noted by many physicists. Feynman, for example, writes: 'I think I can safely 
say that nobody understands quantum mechanics' (1965, p. 129). Research about student difficulties in quantum mechanics have identified how both the new mathematical tools and the 'paradigm shift' in going from classical physics to quantum mechanics present problems to students (Singh \& Marshman, 2015).

Previous research has focused on students' conceptual understanding and problem solving abilities in quantum mechanics (see the review by Singh \& Marshman, 2015). However, quantum mechanics often has a special cultural significance for physics students, stemming from it's role in popular science and popular culture, as well as it's central position in the physics curriculum. The cultural significance of quantum mechanics lies first in that the development of quantum mechanics is an exemplar of 'big' physics history, in which several 'physics heroes' figure. In addition, the continuing difficulties with interpretation (Schlosshauer et al., 2013) and in understanding the formalism serve as inspiration for insider jokes among physics students, as a common topic in popular science, and even as a basis for far-fetched new age theories (Burwell, 2013). To date, little research has focused on the possible impacts of these cultural values on student learning in quantum mechanics. This article shows that even successful and motivated students struggle with making sense of their expectations and experiences of quantum mechanics, and can come away from their first quantum mechanics course with a sense of disillusionment. Some of these issues can be attributed to the cultural significance of quantum mechanics and to the high emotional investment that students place on managing and appreciating the course.

The aim of the current study is to inform teaching practices in quantum mechanics by providing insight into the cultural aspects of the subject. This is done through an investigation of how students respond to ideas and experiences of quantum mechanics and how this influences their perception of themselves and their position in relation to their social context, in this case, their perceived identity as a physicist or physicist-to-be. This study analyses data collected through interviews with international master's students who reflect back on their experiences of taking quantum mechanics, each of them at different universities. The article addresses the research question: How have students' encounters with their first quantum mechanics course influenced their orientation and identification in physics?

\subsection{The teaching of quantum mechanics}

Since the first developments in quantum mechanics in the early 20th century, there has been a discussion of how it can best be taught. In the early days of development, some of these discussions concerned what interpretation and terminology should be used, for instance whether Bohr's notion of complementarity would be more suitable than Heisenberg's notion of uncertainty (Greca \& Freire, 2003). Since the 60s, most quantum mechanics educators have adopted pragmatic approaches to teaching, de-emphasizing interpretational issues and focusing on the mathematical framework (Kaiser, 2002). This approach to teaching quantum mechanics has famously been termed 'shut up and calculate' (Mermin, 1989; Kaiser, 2014). At the same time, something like a consensus about the topics to include in an introductory course seem to have evolved with a widespread use of a few dominant textbooks (in particular 
Undergraduate quantum mechanics: Lost opportunities for engaging motivated students? the text by Griffiths, 2005; Dubson et al., 2009; Siddiqui \& Singh, 2017).

\subsection{Research on quantum mechanics learning}

Quantum mechanics and other advanced courses have been investigated to a lesser extent than introductory courses in physics education research. The increasing volume of results published in the last 20 years have mainly focused on the difficulties students haye with understanding quantum mechanics. This involves mapping 'misconceptions' students have and suggesting ways of overcoming them (see reviews by Falk, 2007; Singh \& Marshman, 2015; Krijtenburg-Lewerissa et al., 2017). One significant result of this work is that the increased mathematical complexity of quantum mechanics allows students to hide their lack of conceptual knowledge behind their mathematical skills even better than students in introductory physics' (Singh \& Marshman, 2015, p. 21). For understanding students' reasoning in quantum mechanics, researchers have employed theoretical frameworks such as epistemological framing (Dini \& Hammer, 2017; Modir et al., 2017) and conceptual metaphors (Brookes \& Etkina, 2007). This research points to how productive reasoning in problem solving is dependent on the frames in which students interpret the problem, and how metaphors used in quantum mechanics may lead students astray when interpreted too literally.

Research on students' attitudes and interest for quantum mechanics paints a rather grim picture. Similar to the situation in many other physics courses (Redish et al., 1998; Adams et al., 2006), in traditionally taught quantum mechanics classes, students have been demonstrated to acquire more novice-like beliefs about the nature of physics and physics learning, and to exit the course less interested than they were when entering it (McKagan et al., 2007; Baily \& Finkelstein, 2015).

While the mainstream research on student difficulties usually do not question the course content or learning goals used, generally accepting the consensus curriculum from the standard textbooks, another research trajectory postulates that the conceptual difficulties stem from the philosophical muddiness of quantum mechanics. This leads to suggestions that quantum mechanics be taught according to alternative interpretations (Greca \& Freire, 2003), or by using alternative terminology (Taber, 2002; Levy-Leblond \& Balibar, 1990).

In recent years, a growing body of research has outlined how issues such as cultural values and students' formation of identities play an important role in learning physics, in addition to purely cognitive learning (Hazari et al., 2010; Irving \& Sayre, 2015; Rodriguez et al., 2015; Gonsalves et al., 2016). In PER, research using the concept identity has for example focused on how membership of minority social categories influences students formation of a 'physics identity' (Hazari et al., 2010), on how physics and masculinity intersect (Gonsalves et al., 2016) and how students learn to become part of a professional community of physicists (Irving \& Sayre, 2015; Rodriguez et al., 2015). A significant finding from studies of identity in the wider field of science education research is that "learning science" is not a neutral activity, but involves processes of dis/identification for those involved' (Archer et al., 2017, p. 742). This means that paying attention to identity issues may very well be important for understanding many classical issues of learning. However, to date, quantum mechanics 


\section{Undergraduate quantum mechanics: Lost opportunities for engaging motivated students?}

education research has not focused on exploring students' experiences of quantum mechanics in relation to culture and identity issues, with one notable exception (Johansson et al., 2016, , see description below).

\subsection{Curriculum reforms}

As mentioned in the previous section, university lecturers tend to agree with the picture of quantum mechanics as especially difficult to understand conceptually, and often choose to focus on just getting the students to know how to handle the mathematical formalism (Dubson et al., 2009; Siddiqui \& Singh, 2017). Concern for students' conceptual difficulties has motivated several initiatives to reform quantum mechanics and 'modern physics' courses, aiming to increase students' conceptual understanding. Work done in the Modern Physics for Engineers courses at CU Boulder focused on implementing interactive engagement techniques and on building solid conceptual understanding (McKagan et al., 2007). Here, connecting the subject to practical applications and engaging students in interpretational issues led to increased student interest (McKagan et al., 2007; Baily \& Finkelstein, 2015).

Another approach to helping students understand quantum mechanics is to start with pure quantum systems, often two-state systems like spin, which also avoids the sometimes overwhelming mathematical problems associated with solving differential equations. This approach is taken in the curriculum and web resources created by the IOP (Kohnle et al., 2014), and was also adopted by some of the instructors in the study by Siddiqui \& Singh (2017). Many efforts to teach quantum mechanics in a more conceptual way for introductory undergraduate and high school students are reviewed in Krijtenburg-Lewerissa et al. (2017).

Baily and Finkelstein (2015) describe an implementation of a curriculum with a larger focus on the philosophical interpretations of quantum mechanics. Their argument is that if teachers do not teach quantum interpretations, students will automatically form their own ontological categories, which can lead to incorrect quantum reasoning. The general problem, identified by many authors, concerns mixing of classical and quantum ontologies (Brookes \& Etkina, 2007; Baily, 2011; Dreyfus et al., 2015). In addition to helping students overcome these difficulties, the reforms of Baily \& Finkelstein (2015) also increased student interest.

Whether, or how, to include the historical developments of quantum mechanics in class is a much disputed topic. One example is the debate about whether the Bohr model should be taught at all or if it is part of a semi-classical baggage that interferes with students' understanding of quantum mechanics (Siddiqui \& Singh, 2017; Krijtenburg-Lewerissa et al., 2017). There is also a risk that the teaching of history in physics becomes a kind of 'quasihistory' that misrepresents the actual scientific process (see Kragh, 1992, for an example of how the theories about the photoelectric effect are usually recounted; cf. Kuhn, 2012/1962). Historical developments can however be a valuable resource if used carefully, helping students understand scientific model building (McKagan et al., 2008; Kragh, 1992). 


\subsection{Studying quantum mechanics through a sociocultural lens}

Students arrive at their first quantum mechanics course with many different notions. For example, in popular culture, quantum mechanics is often portrayed as cool, mysterious and impenetrable, or as able to provide answers to fundamental questions both about the universe and the human condition. These notions can play an important role for physics students choosing to study quantum mechanics and for their identifications as physicists. In order to examine these issues, a sociocultural conceptualization of education can be used, where a focus is put on the social construction of culture and identities (Gee, 2000; Lemke, 2001). In this tradition, culture, institutions, and social relations are viewed as socially constructed in the sense that there is no necessity or naturalness in the way things are (Burr, 2003). On the other hand, socially constructed notions of subjects and identities play an important role in the lives of learners, one pertinent example here is the way in which students are socialized into the norms and practices of a discipline. Research in the sociocultural tradition often focuses on critically assessing the processes of social construction occurring in education to inform possible developments of a more equitable education (Lemke, 2001).

A study aiming to address quantum mechanics learning through a sociocultural lens was conducted by Johansson et al. (2016). The authors analysed classes in quantum mechanics and concluded that students often had high expectations for the course but encountered traditional teaching that emphasized working through standard exercises. This could lead to a kind of anti-climax since students had expected quantum mechanics to be something more than it was. The courses observed in the study presented three practices of doing quantum mechanics to students: exploring, applying, and calculating quantum mechanics. Exploring and applying can be connected to previously mentioned teaching approaches emphasizing model building, interpretation, history, and connections to applications. These practices were however marginal in the courses studied, which more strongly emphasized a more traditional calculating practice, where 'calculate' here refers to a kind of 'plug-and-chug' approach to problem solving (Tuminaro, 2004) with the mathematical tools of quantum mechanics. This approach has been associated with difficulty in scaffolding a solid conceptual understanding for students (cf. Singh \& Marshman, 2015). The opportunities for being a 'good physics student' in these courses were limited to being good at 'calculating', which often fails to take the various interests, competences, and aspirations of the students into account. The authors suggest that implementing curriculum reforms with an increased focus on exploring or applying quantum mechanics, in line with some of the reforms mentioned in the last section, could improve this situation. These results serve as a background for the analysis in this article.

\section{Materials and methods}

This article draws on interviews with 8 students conducted as part of a study on experiences and norms in physics master's programmes at two Scandinavian universities. All students were interviewed in their first semester of studies and had received their bachelor's degrees (all 


\section{Undergraduate quantum mechanics: Lost opportunities for engaging motivated students? 6}

in physics except Bo in materials science) in their home countries. The national background of the students were Belgian (one), Chinese (one), German (one), Greek (two), Italian (one), and Mexican (one). One student (Sara) identified as a woman and the others as men. Everyone except one of the students belonged to the ethnic majority of their home country, where they had all spent most of their lives. The topic of the interviewees' current master's studies are listed in Table 1.

The interviews were semi-structured, lasted between 50 and 100 minutes and focúsed on three broad themes: Experiences of studying physics, experiences of starting on the master's programme and ideas about what it means to be a physicist. In relation to these general topics, the interviews addressed students' experiences of taking quantum mechanics in their bachelor's programme. The interviews were recorded and transcribed. The parts of the interviews discussing quantum mechanics were analysed with a focus on how the interviewees described their experiences, emotions and negotiations in relation to the quantum mechanics course. Together with this, the full, situated story provided in each interview was taken into account as a background to each interviewee's identity negotiations. In the previous study (Johansson et al., 2016), the experiences of students taking their first quantum mechanics course were analysed by observing classes and interviewing students at the time of the course. In order to more completely analyse the role of quantum mechanics in students' pathways into physics, this study puts a focus on how students relate back to the course a few years later. While the stories students tell may well change over the years and be adapted to the situation (Holmegaard et al., 2015), the focus of this analysis is on students' own sense-making of their experiences and not on an exact representation of events. In this way, the accounts of students at the time of the interview are enlightening.

The analysis was carried out in an interpretative thematic manner (Flick, 2009), where each interviewee's story was treated as a case that was compared with the others. All discussions of quantum mechanics were coded in an open-ended way with one or several codes, labelling students' different experiences, conceptions and emotions etc. related to quantum mechanics (Bogdan \& Biklen, 2007). Some examples of the codes used were: 'quantum mechanics as enticing', 'quantum mechanics is difficult', 'quantum mechanics is nerdy', 'deeper understanding', 'changed feelings'. Using these codes as a guide to the material, each interviewee's account was analysed focusing on identity negotiations in relation to the quantum mechanics course. This analysis yielded common themes of expectations, attraction and/difficulty (seen in all interviews), and two ways that students described they had responded to taking quantum mechanics (clearest for four of the students).

\section{Results}

The central findings of this article are two qualitatively different ways of responding to taking quantum mechanics that occur in the interviewees' narratives. These two responses are particularly prominent in four of the interviews Before describing the two responses, some common themes in all the interviews, will be described.

The interviewees received their bachelor's degrees in seven different countries, but 
Table 1. The interviewed students and the topic of their master's studies

\begin{tabular}{ll}
\hline Interviewee & Topic of master's \\
\hline Ivo & Theoretical physics \\
Elias & Biophysics \\
Valter & Meteorology \\
Sara & Nuclear physics \\
Alex & Materials physics \\
Jan & Theoretical physics \\
Bo & Materials theory \\
Dan & Geophysics \\
\hline
\end{tabular}

described similar first quantum mechanics courses, which suggests that there is some sort of international consensus around teaching practice. The first course usually involves being introduced to the Schrödinger formulation of quantum mechanics and doing exercises based on the Schrödinger equation, and this traditional approach with lectures and exercise sessions seemed to be what the interviewees had encountered.

All the interviewees recognize the centrality of quantum mechanics to modern physics, and know that it is important for them to have learned it and passed the course. In line with the research about student difficulties described above, the interviewees perceive quantum mechanics as a difficult subject, both regarding conceptual understanding and mathematical problem solving. In addition to this, quantum mechanics is described as a subject that can spark an interest in physics. Most of the interviewees entered the bachelor's programme with a general interest in physics but without a clear idea about what kind of physics they would focus on. Quantum mechanics has however been a source of inspiration for several of them, and can be ascribed a central role in their decision to study physics. Bo, who started his university education in a materials science programme, took a mandatory quantum mechanics course and found that it seemed to point to a deeper understanding than the rest of his education. He says that this was one of the reasons for him to subsequently switch to physics.

Quantum mechanics, or, more generally quantum physics, is described as a source of interest in physics already in the interviewees' teenage years. Both Sara and Valter explain how a fascination with quantum physics made them want to study physics. Valter, who studied an informatics programme in high school was inspired when he attended a class there about quantum computing. He says that 'I was very fascinated about this and I saw it as the way to follow my purpose of studying physics'. Jan expresses a similar fascination with physics being sparked when he as a young teenager read the fantasy novels His Dark Materials, whose universe is inspired by quantum physics (Pullman, 1995-2000). This led him to want to understand what it was all about, how the world worked.

Several interviewees also reflected on the fact that quantum physics has a special appeal also to people who don't study physics, but that sometimes they may draw far-fetched conclusions from it, something that physics students should avoid. For example, Bo explains 
Undergraduate quantum mechanics: Lost opportunities for engaging motivated students? 8

that he thinks Schrödinger's cat is 'a cool story for popular science' but that he thinks that 'students shouldn't be satisfied with too popular science. [It's] not real science'.

In the interviewees' accounts of their studies of quantum mechanics, two ways of responding to the course could be identified, here labelled 'acceptance' and 'withdrawal'. Four of the students' descriptions of their ways of handling the course are clearly dominated by one way or the other. Excerpts from these interviews illustrate the account below. The other four students describe their views and experiences of quantum mechanics, móstly as a calculating course; how they make sense of this in a deeper sense is not clear from the interviews.

\subsection{Responding with acceptance}

Students' expectations about their education may not always be realistic, and, as previous research suggests, this may be especially pronounced when it comes to quantum mechanics (Johansson et al., 2016). Two of the interviewees explicitly discuss the expectations that people could have for quantum mechanics and how they themselves, rather than being disappointed, simply accept things the way they are.

Ivo recognizes that high expectations for quantum physics can be connected to the popular science ideas of his non-physicist peers, and compares this to his own experiences as a physics student:

I think usually people from outside physics, they expect 'oh you're gonna understand everything if you do quantum physics'. But if you go there you learn things about, I don't know, angular momentum algebra or something and eh ... very abstract mathematical notation, but then you still haven't applied it to anything in the real world.

Ivo recognizes that he has to accept this situation in some way to succeed. As a physics student, he adds, you need to have a more 'practical approach', being prepared to learn 'how to deal with the mathematical framework of quantum mechanics' but not expect the quantum mechanics professor to 'explain the world' to you.

Alex expresses similar sentiments when he points out the difficulty of understanding quantum mechanics:

At first you say 'it's ok ... it's like classical mechanics but eh ... you look at it in a different way'. But as you go deeper and deeper, you see changes and you see that there is a change of possibilities and you can have the beam and then you have the transmitted and the reflected [beams] but then where you only have a transmitted then you will have a reflected beam too. And then you start to say 'ok this is totally counterintuitive' (laugh) you have to read it again and read it again and read it again. Then you go deeper and deeper and then you realize again that you know nothing (big laugh).

Alex describes a similar way of handling the course to Ivo's, saying that in studying quantum mechanics, it is best to just try to understand it through mathematics: 'I don't think that we 
Undergraduate quantum mechanics: Lost opportunities for engaging motivated students?

can ever understand it if we don't look into it entirely mathematically. That's the only way, and all the examples are wrong (laugh). I mean the visual examples.'

However, learning quantum mechanics mathematically can be experienced in/different ways. With the traditional instruction the interviewees have received, most have experienced it as doing end-of-chapter exercises. Elias, studying biophysics, is critical of his earlier programme, which contained too many 'how to solve exercises-exams' which did not help him learn 'the actual physics behind the stuff'. He admits though that 'probably quantum mechanics cannot escape this kind of exam', implying that the necessary mathematical complexity of quantum mechanics means it has to be taught and examined through working out mathematical exercises.

Ivo and Alex both clearly describe how they handle quantum mechanics by accepting the practice of the course, accepting that they will never 'really understand', except perhaps for the mathematics. This approach can be characterized as accepting a kind of 'shut up and calculate'-attitude to quantum mechanics (Kaiser, 2014).

\subsection{Responding with withdrawal}

The quantum mechanics course may also be experienced as providing too few opportunities to learn what one expected from it. This experience is exemplified by Valter and Sara, who both in some sense withdrew from quantum mechanics and their aspirations for learning it. They were both drawn to quantum physics when they were in high school. When starting their university education, Sara and Valter say that they were interested in theoretical physics and quantum informatics, respectively. Sara was sure quantum mechanics would be 'awesome' but experienced an anti-climax when she had trouble managing the studies:

In fact when I was in high school I was always thinking 'oh, when I'm in bachelor I will study quantum physics and I will understand everything and it will be so awesome' and I was very excited. But then when I took it the first time, like it was a combination of that I wasn't like feeling good in that semester and also it was a difficult subject so I had to pay attention. But I was not really into school in that time so ... I was very disappointed and I started to hate it and I was sad because I thought 'I just came here to study physics to study quantum mechanics and now I don't like it. Why? What's wrong?'

Valter describes a similar anti-climax when the quantum course did not live up to his expectations of being the best course of all:

Yeah, it's of course the best one, the one that I wanted to go there everyday and just wait in front of the door for the professor and ask questions. But finally, it was not that way. Maybe ... of course the professor had a role in it, because he was not so good at explaining.

The emotional response to this anti-climax is described by Valter as follows: 'eh ... I think I don't hate quantum physics [...] actually I don't love it as much as I thought I would'. 
Undergraduate quantum mechanics: Lost opportunities for engaging motivated students? 10

Taking quantum mechanics was a troubling experience for both Valter and Sara, which changed their views of both physics and themselves. One result of this reorientation is that both chose to study other physics subjects than they had expected, subjects where they could more clearly understand how everything made sense and how they could use it. For example, Valter explains that in meteorology 'you see what are you doing, while sometimes in other fields of physics you have to more trust your equation than see that they are effectively working'. Making these choices in effect means that, these students had to reinterpret their physics identity.

For both Valter and Sara, this change of plans and reinterpretation of their identity as physics people implies a loss of status. Valter reflects on how he may be viewed as less smart now that he studies meteorology and that 'people will be more impressed if I say that I study physics [instead of meteorology]'. In particular, quantum physics is highly regarded by people outside physics: 'So if you say that you study quantum physics you are damn, the best people in the world, you know everything, you are so smart. Please explain that thing about the cats'. Sara wanted to become a theoretical physicist, but changed her plans and did her bachelor's project in a multidisciplinary setting. She points out that this makes her feel like less of a physicist overall.

Despite their negative experiences of quantum mechanics, both Sara and Valter completed the course and gained their bachelor's degrees. For a while, Sara thought about avoiding quantum mechanics in her continued studies but is now taking a second course:

After the first course that I took I was like 'I will never ever take anything related to this again'. But now (laughing) I' $m$ here. Yeah, my friends laugh about it because they tell me like: 'oh hey, you told us that you hated it, so now you're taking the advanced course?'

Valter also expresses a wish to learn more quantum mechanics, even though he currently studies other subjects. While the experiences of Sara and Valter have led them to withdraw from a study trajectory focused on quantum mechanics, and from their earlier emotional investments in learning it, they have not departed from physics, nor totally abandoned their interest in quantum mechanics.

The two types of response to taking quantum mechanics - acceptance and withdrawalfound in this study signal changes in students' emotional investment and future study plans. Clearly, these two responses do not capture all student attitudes to quantum mechanics, however, they do point to significant differences in feelings of affiliation to quantum mechanics.

\section{Discussion}

The results of this study reinforce the picture of the first quantum mechanics course as an important step on students' paths to becoming physicists. This is not only because of the formal role of quantum mechanics in the curriculum but also due to the significance it is ascribed as an intriguing and fascinating subject that only smart people can understand. For 


\section{Undergraduate quantum mechanics: Lost opportunities for engaging motivated students? 11}

these reasons, the first quantum mechanics course becomes a critical event for students' future physics trajectories, where they invest a lot in managing it and putting it in a meaningful context of becoming the physicist they want to be. This strong investment, which is also an investment in a physics identity, can lead to a kind of 'identity crisis' if students' experiences of the course do not live up to their expectations. While some students in this study accepted the way of learning quantum mechanics that their courses presented, others appear to have experienced a crisis and partially withdrew from quantum mechanics. Thus, whilst all the students interviewed in this study successfully completed the course and continued their physics studies, for some, this progress involved a significant re-evaluation of their view of quantum mechanics and themselves.

\subsection{Evaluating the responses of the students}

The interviewees implicitly evaluate their experiences and choices as failures or successes. Alex and Ivo describe how they have accepted the way things are taught, managed the course, and continued their studies along their chosen path, which is at least a success within the educational system. In contrast, Valter and Sara have reconsidered their choices and withdrawn from the path in physics they envisioned. Subsequently they opted for paths with, from their point of view, lower status, in a sense failing to achieve what they originally planned. How should we as physicists and physics educators interpret these responses? What behaviour and attitudes would we like our students to exhibit?

Some of the preconceptions students may have about quantum mechanics as cool, mysterious or able to provide deep insight can certainly be viewed as naive. In this respect, leaving exaggerated expectations behind and accepting 'the way things are done in physics' is a step we expect our students to take on their path to becoming physicists. However, the acceptance response may also involve students giving up on the possibilities of deep learning in quantum mechanics. The dangers of such an approach have been highlighted in research which shows that students can take on less expert-like views about learning physics after standard instruction. That is, after instruction, students view physics as less coherent, less connected to reality, and as more dictated by authorities (Redish et al., 1998; Adams et al., 2006). These unproductive beliefs may be promoted by an accepting approach to physics learning that involves taking the physics content presented at face value.

Thus, the crisis and withdrawal response of Sara and Valter can be interpreted as a refusal to abandon their goal of deep understanding. They both managed the quantum mechanics course, but afterwards chose to study areas where they could feel a closer connection and deeper understanding of the material. This response thus signals a commitment to learning that we would like to encourage in physics students. In introductory quantum mechanics, there is some value in being able to accept the material for what it is and just 'shut up and calculate', but this should not be allowed to dampen the desire for deeper understanding. Similar to my interviewees' experiences, one student's struggles with these epistemological issues is described in detail Dini \& Hammer (2017).

Thus, evaluating the motivations, attitudes and responses of the students in this 


\section{Undergraduate quantum mechanics: Lost opportunities for engaging motivated students? 12}

study leads to a picture where acceptance does not necessarily represent total success and withdrawal does not necessarily represent total failure. Rather, the picture is complex with the approaches and attitudes of both groups of students being deemed valuable for different reasons. This is perhaps unsurprising since all the students in the study are "successful" physicists and it is therefore interesting to speculate on the possible effects of these two approaches with respect to the trajectories of 'unsuccessful' students.

\subsection{Implications for quantum mechanics teaching}

As the results describe, quantum mechanics is a subject where students arrive with high expectations, and at the same time a subject where a tension between deep conceptual understanding and 'shutting up and calculating' seem inherent. All this can at times combine to make the course a troubling experience for students. The question then is whether quantum mechanics teaching could do more to avoid disheartening these students and instead make the most of their initial enthusiasm. At the same time, could reformed quantum mechanics teaching avoid leaving students with the notion that they will never really understand it and instead help them develop a sound framing of the limits of knowledge? Clearly, some of the curriculum reforms and resources described in the introduction point to part of the solution.

The traditional approach to teaching quantum mechanics, primarily focusing on the mathematical formalism, means that being good at quantum mechanics mainly involves comprehending and working out end-of-chapter exercises. Whilst this mathematical formulation is a necessary tool that all physics students must master, there are risks with this traditional teaching approach. Research has shown that an over-emphasis on doing standard text-book problems means that students can get away without a solid understanding (Singh $\&$ Marshman, 2015). This may also lead to notions of the overall process of problem solving as simple 'plug-and-chug' (Maloney, 2011). These issues of conceptual understanding and approaches to quantum mechanics have been well-described in the literature. However, in this paper it has been demonstrated that even successful students can move on from quantum mechanics instruction with a sense of disillusionment and decreased motivation. This in turn leads to a renegotiation of their physics identity. Apart from the previously well-documented problems of conceptual understanding in quantum mechanics, students' identification or disidentification with quantum mechanics can thus play a significant role in their experience and learning in the course and for their future career. Both these issues need to be considered when teaching quantum mechanics, and a first step towards increasing enthusiasm and engagement in the course can be an awareness of students preconceptions and hopes, addressing these explicitly, something which can at times mean managing exaggerated expectations,

Whilst the curriculum reforms described in the introduction have been designed to address the problem of students' lack of conceptual understanding, some of them might also help students with developing desirable attitudes and beliefs about physics, and in negotiating viable physics identities. For example, helping students build their own knowledge through interactive engagement techniques focused on conceptual understanding has generally been 

successful both for learning and engagement (Redish, 2003) and this can be expected to be the case for quantum mechanics as well (McKagan et al., 2007). The 'withdrawing' students in this study, while experiencing quantum mechanics as a difficult course, also were disappointed as it did not seem to be able to provide them with the deep understanding that they expected. Emphasizing conceptual understanding through interactive engagement may give students better opportunities to construct their own understanding, and in that way appreciate what they can and cannot learn at a particular stage in their studies.

Another reform that has been suggested involves putting a greater emphasis on interpretation. This approach has been shown to increase student interest in quantum mechanics (Baily \& Finkelstein, 2015). Here, teachers deliberately introduced tricky questions of interpretation, sometimes by having students read and discuss research or popular articles, and then helped with (correct) interpretations in class. This approach can be contrasted with the avoidance of interpretational issues displayed by some of the lecturers in the study of Siddiqui \& Singh (2017). In addition, in the courses designed and studied by Baily \& Finkelstein (2015), one part of the examinations was an essay where students could explore an issue of their choice, something which allowed room for students' own interests. It is of course impossible to know whether this approach would have the same effect on physics students as it had on engineering majors. However, the eight successful physics graduates interviewed in this study all mention the intriguing nature of quantum mechanics as an initial motivation to study the course. Thus it is argued that addressing interpretational issues more explicitly in courses and allowing students to explore these themselves may be a way of harnessing this initial interest.

Finally, historical, multidisciplinary and applications approaches to teaching quantum mechanics may also be a way of picking up on the interest students enter with. These kinds of approaches could be used to encourage scientific thinking in terms of model building etc. (McKagan et al., 2008; Kragh, 1992).

\section{Conclusions}

This article expands the discussion of how to teach quantum mechanics to include issues about the significance that students ascribe to the subject and how this influences their experiences of the course. Quantum mechanics is a subject that attracts students to physics, but we also risk disappointing them severely when their interest and engagement is not commensurate with the way in which quantum mechanics is taught. The traditional teaching of quantum mechanics encountered by the students in this study does little to avoid these risks, encouraging only those students who can adopt a 'shut up and calculate' attitude to learning physics.

There are ways to overcome these problems and provide for a broader range of students with various interests and motivations in quantum mechanics courses. One viable approach is to adopt some of the curriculum reforms described in this article. Raising awareness of these issues is equally important. Clearly it is up to each individual quantum mechanics lecturer to decide what will work best for their particular group of students. However, when making pedagogical choices the findings of this article suggest that an understanding of 
Undergraduate quantum mechanics: Lost opportunities for engaging motivated students? 14 students' initial motivations and the defining nature of the quantum mechanics course for future student trajectories should be considered. The goal should be to leverage our students' initial excitement and motivation to help them build deep conceptual understanding and at the same time construct a viable physics identity.

\section{Acknowledgements}

Thanks to all colleagues who have read and commented on the manuscript at different stages. Special thanks to Staffan Andersson, John Airey, Maja Elmgren, Johanna Larsson, Arnold Pears, and Minna Salminen-Karlsson.

\section{References}

Adams, W. K., Perkins, K. K., Podolefsky, N. S., Dubson, M., Finkelstein, N. D. \& Wieman, C. E. (2006) New Instrument for Measuring Student Beliefs about Physics and Learning Physics: The Colorado Learning Attitudes about Science Survey. Phys. Rev. ST Phys. Educ. Res. 2010101.

Archer, L., Dawson, E., DeWitt, J., Godec, S., King, H., Mau, A., Nomikou, E. \& Seakins, A. (2017) Killing Curiosity? An Analysis of Celebrated Identity Performances among Teachers and Students in Nine London Secondary Science Classrooms. Sci. Ed. 101 $741-764$.

Baily, C. (2011) Perspectives in Quantum Physics: Epistemological, Ontological and Pedagogical. Ph.D. Thesis. University of Colorado. http: / / www . colorado . edu / physics/EducationIssues/baily/dissertation/

Baily, C. \& Finkelstein, N. D. (2015) Teaching Quantum Interpretations: Revisiting the Goals and Practices of Introductory Quantum Physics Courses. Phys. Rev. ST Phys. Educ. Res. 11020124.

Bogdan, R. \& Biklen, S. K. (2007) Qualitative Research for Education: An Introduction to Theories and Methods. 5th ed. Boston, Mass: Pearson A \& B. 304 pp.

Brookes, D. T. \& Etkina, E. (2007) Using Conceptual Metaphor and Functional Grammar to Explore How Language Used in Physics Affects Student Learning. Phys. Rev. ST Phys. Educ. Res. 3010105.

Burr, V. (2003) Social Constructionism. London: Routledge.

Burwell, J. (2013) Figuring Matter: Quantum Physics as a New Age Rhetoric. Sci. Cult. 22 344-366.

Dini, V. \& Hammer, D. (2017) Case Study of a Successful Learner's Epistemological Framings of Quantum Mechanics. Phys. Rev. Phys. Educ. Res. 13010124.

Dreyfus, B. W., Sohr, E. R., Gupta, A. \& Elby, A. (2015) "Classical-Ish": Negotiating the Boundary between Classical and Quantum Particles. 2015 PERC Proceedings. Ed. by A. Churukian, D. L. Jones \& L. Ding. College Park, MD, 111-114. DOI: 10 . 1119 / perc. 2015 .pr.023. 
Undergraduate quantum mechanics: Lost opportunities for engaging motivated students? 15

Dubson, M., Goldhaber, S., Pollock, S. \& Perkins, K. (2009) Faculty Disagreement about the Teaching of Quantum Mechanics. 2009 PERC Proc. Ed. by M. Sabella, C. Singh \& C. Henderson. AIP Conf. Proc. 1179. Ann Arbor, MI, 137-140. DOI: 10 . 1063/1. 3266697.

Falk, J. (2007) Students' Depictions of Quantum Mechanics: A Contemporary Review and Some Implications for Research and Teaching. Licentiate Thesis. Uppsala universitet. http://urn.kb.se/resolve?urn=urn:nbn: se: uu:diva-85826

Ferdinande, H. (2009) A European Specification for Physics Bachelor Studies. EPS Publications. http: / / www . eps . org / resource / resmgr/policy / eps_ specification_bphys.pdf

Feynman, R. (1965) The Character of Physical Law. Cambridge, Mass.: The M.I.T. Press.

Flick, U. (2009) An Introduction to Qualitative Research. SAGE. 529 pp.

Gee, J. P. (2000) Identity as an Analytic Lens for Research in Education. Rev. Res. Educ. 25 99-125.

Gonsalves, A. J., Danielsson, A. \& Pettersson, H. (2016) Masculinities and Experimental Practices in Physics: The View from Three Case Studies. Phys. Rev. Phys. Educ. Res. 12 020120.

Greca, I. M. \& Freire Jr., O. (2003) Does an Emphasis on the Concept of Quantum States Enhance Students' Understanding of Quantum Mechanics? Sci Educ 12 541-557.

Griffiths, D. J. (2005) Introduction to Quantum Mechanics. 2nd ed. Upper Saddle River, NJ: Pearson Prentice Hall.

Hazari, Z., Sonnert, G., Sadler, P. M. \& Shanahan, M.-C. (2010) Connecting High School Physics Experiences, Outcome Expectations, Physics Identity, and Physics Career Choice: A Gender Study. J. Res. Sci. Teach. 47 978-1003.

Holmegaard, H. T., Ulriksen, L. \& Madsen, L. M. (2015) A Narrative Approach to Understand Students' Identities and Choices. Understanding Student Participation and Choice in Science and Technology Education. Ed. by E. K. Henriksen, J. Dillon \& J. Ryder. Springer Netherlands, 31-42. DOI: 10.1007/978-94-007-7793-4_3.

Irving, P. W. \& Sayre, E. C. (2015) Becoming a Physicist: The Roles of Research, Mindsets, and Milestones in Upper-Division Student Perceptions. Phys. Rev. ST Phys. Educ. Res. 11020120.

Johansson, A., Andersson, S., Salminen-Karlsson, M. \& Elmgren, M. (2016) "Shut up and Calculate": The Available Discursive Positions in Quantum Physics Courses. Cult Stud of Sci Educ DOI: 10.1007/s11422-016-9742-8.

Kaiser, D. (2002) Cold War Requisitions, Scientific Manpower, and the Production of American Physicists after World War II. Hist Stud Phys Biol Sci 33 131-159.

Kaiser, D. (2014) History: Shut up and Calculate! Nature 505 153-155.

Kohnle, A., Bozhinova, I., Browne, D., Everitt, M., Fomins, A., Kok, P., Gytis Kulaitis, Prokopas, M., Raine, D. \& Swinbank, E. (2014) A New Introductory Quantum Mechanics Curriculum. Eur. J. Phys. 35015001.

Kragh, H. (1992) A Sense of History: History of Science and the Teaching of Introductory Quantum Theory. Sci Educ 1349-363. 
Undergraduate quantum mechanics: Lost opportunities for engaging motivated students? 16

Krijtenburg-Lewerissa, K., Pol, H. J., Brinkman, A. \& van Joolingen, W. R. (2017) Insights into Teaching Quantum Mechanics in Secondary and Lower Undergraduate Education. Phys. Rev. Phys. Educ. Res. 13010109.

Kuhn, T. S. (2012/1962) The Structure of Scientific Revolutions. 4th ed. Chicago: The University of Chicago Press.

Lemke, J. L. (2001) Articulating Communities: Sociocultural Perspectives on Science Education. J. Res. Sci. Teach. 38 296-316.

Levy-Leblond, J.-M. \& Balibar, F. (1990) Quantics: Rudiments of Quantum Physics. Amsterdam; New York: North Holland.

Maloney, D. (2011) An Overview of Physics Education Research on Problem Solving. Getting Started in PER. Ed. by C. Henderson \& K. A. Harper. Vol. 1. Reviews in PER 2. College park, MD: American Association of Physics Teachers. ht tp : / / www p percentral.org/items/detail.cfm? ID=11457

McKagan, S. B., Perkins, K. K. \& Wieman, C. E. (2007) Reforming a Large Lecture Modern Physics Course for Engineering Majors Using a PER-Based Design. 2006 PERC Proc. AIP Conf. Proc. 883. Syracuse, New York, 34-37. DOI: 10.1063/1.2508685.

McKagan, S. B., Perkins, K. K. \& Wieman, C. E. (2008) Why We Should Teach the Bohr Model and How to Teach It Effectively. Phys. Rev. ST Phys. Educ. Res. 4010103.

Mermin, N. D. (1989) What's Wrong with This Pillow? Phys. Today 42 9-11.

Modir, B., Thompson, J. D. \& Sayre, E. C. (2017) Students' Epistemological Framing in Quantum Mechanics Problem Solving. Phys. Rev. Phys. Educ. Res. 13020108.

Pullman, P. (1995-2000) His dark materials. Book series. Scholastic.

Redish, E. F. (2003) Teaching Physics with the Physics Suite. Hoboken, NJ: Wiley.

Redish, E. F., Saul, J. M. \& Steinberg, R. N. (1998) Student Expectations in Introductory Physics. Am. J. Phys. 66 212-224.

Rodriguez, I., Goertzen, R. M., Brewe, E. \& Kramer, L. H. (2015) Developing a Physics Expert Identity in a Biophysics Research Group. Phys. Rev. ST Phys. Educ. Res. 11 010116.

Schlosshauer, M., Kofler, J. \& Zeilinger, A. (2013) A Snapshot of Foundational Attitudes toward Quantum Mechanies. Stud. Hist. Philos. Sci. Part B Stud. Hist. Philos. Mod. Phys. $44222-230$.

Siddiqui, S. \& Singh, C. (2017) How Diverse Are Physics Instructors' Attitudes and Approaches to Teaching Undergraduate Level Quantum Mechanics? Eur. J. Phys. 38 035703.

Singh, C. \& Marshman, E. (2015) Review of Student Difficulties in Upper-Level Quantum Mechanics. Phys. Rev. ST Phys. Educ. Res. 11020117.

Taber, K. S. (2002) Conceptualizing Quanta: Illuminating the Ground State of Student Understanding of Atomic Orbitals. Chem. Educ. Res. Pract. 3 145-158.

Tuminaro, J. (2004) A Cognitive Framework for Analyzing and Describing Introductory Students' Use and Understanding of Mathematics in Physics. Ph.D. Thesis. University of Maryland. http: / / hdl. handle.net/1903/1413 